\title{
A formação de um Exército à brasileira: lutas corporativas e adaptação institucional
}

The formation of an Army in Brazilian way: corporate disputes and institutional adaptation

Ernesto SEIDL・

Resumo: O artigo aborda o processo de formação do Exército brasileiro no período 1850-1930 e discute o desenvolvimento de perspectivas de análise capazes de integrar, ao estudo de instituições e de elites, as condições históricas e culturais específicas das sociedades em que se inserem. Assim, busca afinar as discussões em torno da composição e recomposição de grupos dirigentes no Brasil, especialmente de elites burocráticas ou de Estado. A análise procura redimensionar elementos da dinâmica de construção nacional e de sua história social (criação de instituições, elaboração de representações, formação de elites dirigentes, reconstituição das disputas entre grupos). Por fim, o trabalho explora as relações entre as esferas militar, política e intelectual e as lógicas nelas acionadas nos confrontos pelos espaços de poder.

Palavras-chave: Exército Brasileiro; Construção Nacional; Reprodução Social; Política.

Abstract: The article is focused on the process of formation of the Brazilian Army from 1850 to 1930. It also seeks to discuss the development of analytical perspectives which are able to integrate, to the study of institutions and elites, the specific historical and cultural conditions from societies which are inserted. Thus, it aims to attune the discussions about the formation and rearrangement of Brazil's ruling groups, especially of bureaucratic elites or the State. The analysis seeks to resize elements of the dynamics of nation building as well as its social history (institution-building, social representations, formation of ruling elites, reconstitution of the disputes between groups). Finally, the work explores the relationship among the military, political and the intellectual spheres and the logics embedded in them in confrontations for clashes of power.

Keywords: Brazilian Army; National Building; Social Reproduction; Politics.

Se grande parte da produção acadêmica e semiacadêmica dedicada à história do Exército no Brasil converge na visão de uma progressiva profissionalização da carreira militar a partir da metade do século XIX, são, contudo, raros os estudos que problematizam o que poderia ser tomado como evolução inequívoca em direção aos moldes burocratizados de modelo militar e à imposição da meritocracia como princípio de ascensão no oficialato brasileiro. Embora sejam claras as indicações de que a adoção crescente de critérios formais de evolução hierárquica passasse a vincular o avanço no ranking militar à obtenção obrigatória de formação escolar nos cursos preparatórios ao oficialato que eram sucessivamente criados, um exame detido das bases sociais do recrutamento do oficialato, das engrenagens de sua seleção e dos mecanismos práticos acionados pelos agentes sociais ao longo do período permite que se matizem afirmações dessa natureza.

\footnotetext{
- Professor Doutor - Departamento de Ciências Sociais e do Programa de Pós-Graduação em Sociologia - Centro de Educação e Ciências Humanas - UFS - Univ. Federal de Sergipe - Av. Marechal Rondon, s/n, CEP: 49100-000, São Cristovão, SE, Brasil. Pesquisador do LEPP - Laboratório de Estudos do Poder e da Política da UFS. A pesquisa que resultou neste artigo contou com financiamento do CNPq. Email: eseidl@terra.com.br
} 
$\mathrm{Na}$ base de tal problematização está um conjunto de questões ligadas às condições de constituição e de funcionamento da dinâmica do poder, assim como do aparato estatal e de instituições burocráticas (mas também de outras instituições, profissões) em contextos sociais periféricos - importadores de modelos de países centrais. Seguindo a hipótese dos efeitos de importação sofridos por bens simbólicos (ideologias, filosofias, instituições, princípios estéticos) adotados em contextos diversos daqueles que se constituíram historicamente, trata-se de tentar escapar de abordagens meramente centradas na "evolução" das regras formais, na implementação de novos regulamentos e na expansão do sistema escolar do Exército e de investir na compreensão dos amálgamas e rearranjos específicos criados pela lógica da sobreposição cultural.

Nessa trilha de análise, este artigo procura explorar três eixos principais de discussão: em primeiro lugar e num plano mais geral, busca-se afinar as discussões em torno dos processos de formação e de recomposição de grupos dirigentes no Brasil, em especial, de elites burocráticas ou de Estado; diretamente conectado a este aspecto, entra em conta a tentativa de desenvolvimento de perspectivas de análise capazes de integrar ao estudo de instituições e de elites as condições históricas e culturais específicas das sociedades em que se inserem. Como mencionado mais acima, trata-se de considerar os efeitos próprios de condições sociais periféricas, como as da sociedade brasileira, e de redimensionar, por essa via, elementos da dinâmica de construção nacional e de sua história social (criação de instituições, elaboração de representações, formação de elites dirigentes, reconstituição das disputas entre grupos); um terceiro eixo de interesse busca investigar, em especial, as relações entre as esferas militar, política e intelectual e as lógicas nelas acionadas nos confrontos pelos espaços de poder.

\section{Transformações no sistema escolar e redefinições da carreira militar}

Comumente apontada pela bibliografia ${ }^{1}$ como ponto de inflexão na estruturação da carreira militar, a série de modificações introduzidas no Exército a partir da metade do século XIX traduz nitidamente uma preocupação em se criar padrão mais formalizado da profíssão. Inspirados em práticas europeias consideradas modernas, a lei e os regulamentos adotados pelo Exército Imperial em 1850 passavam a vincular a ascensão na hierarquia a regras institucionais formalmente explicitadas. Desse modo, seguindo uma tendência de modernização experimentada pelos exércitos ocidentais - burocratização, critérios rígidos de ascensão interna, escolarização e tecnificação -, criavam-se medidas objetivamente destinadas a romper com os mecanismos até então frouxos e pouco objetivos de regulação hierárquica. Em outras palavras, apontava-se para a eliminação dos "vícios" personalistas e aristocráticos típicos do regime imperial, essencialmente ancorados nas relações de privilégio estabelecidas entre o poder central e frações aptas a desfrutar de acesso e 
proximidade àquela esfera (proprietários fundiários, nobreza de origem europeia, burocracia "lusa" e brasileira).

Dentre o mencionado conjunto de modificações visando à regulação do acesso aos postos de oficiais das diferentes armas, oficializado por lei imperial assinada em setembro de 1850 e regulamentado por decreto de março do ano seguinte, são destacados os seguintes aspectos: a gradualidade na ascensão hierárquica, desde o posto de alferes ou segundo-tenente até o de marechal; os limites mínimos da idade de dezoito anos e de dois anos de praça efetiva para a promoção ao posto de alferes ou de segundo-tenente; a obrigatoriedade, para a promoção até o posto de capitão, da obtenção do curso completo da respectiva arma, além da antiguidade de dois anos no posto atual; um serviço mínimo de três anos no posto imediatamente anterior ao de acesso aos postos superiores (para o serviço em atividades de guerra, o tempo previsto nos últimos dois pontos seria reduzido à metade, e ainda suas condições poderiam ser modificadas por serviços relevantes e ações de bravura e inteligência devidamente justificadas); o preenchimento dos postos de tenente e capitão seria conferido por antiguidade, os de major, tenente-coronel e coronel, metade por esse princípio e metade por merecimento ${ }^{2}$, e os postos de oficiais-generais (brigadeiro, general e marechal) exclusivamente por merecimento, a juízo do governo; inclusão da contagem de antiguidade militar do tempo passado em serviço na Guarda Nacional, corpos policiais, Marinha, missões diplomáticas, presidências de províncias, ministérios, corpo legislativo, ou ainda em atividades, dentro ou fora do Império, dedicadas aos estudos militares ou industriais com permissão do Ministério da Guerra; proibição da concessão de graduações (exceto ao oficial mais antigo de cada classe), incluindo graduações militares, a empregados civis das secretarias, contadorias, arsenais e outros estabelecimentos ou repartições militares, com exceção dos pagadores e comissários das tropas ${ }^{3}$.

De par com essas inovações estava a ampliação do sistema de ensino militar - tornado aspecto central no interior da instituição -, uma vez que o estudo adquiria dimensão importante na estruturação da carreira (de acordo com a lei de 1850, o curso de uma das armas era condição indispensável para as promoções até o posto de capitão), ao contrário do que ocorria no sistema vigente desde 1810, inaugurado com a criação da Real Academia Militar na Corte. Até então, esta havia sido a única instituição de ensino dedicada ao Exército e formava, além de oficiais de armas (infantaria, cavalaria e artilharia), oficiais engenheiros, engenheiros geógrafos e topógrafos, estes últimos também habilitados para serviços civis. Em 1844, uma reforma estatutária estabeleceu os títulos de bacharel e doutor em ciências matemáticas, criando o "tipo híbrido do militar-bacharel, ou militar-doutor". Como aponta Motta (1976, p. 79), "através dele [o título] sente-se que os quartéis não ficaram imunes à feitiçaria dos títulos a que todo o Império, aos poucos, se entregava. 
Todo mundo queria ser doutor. O título abria caminho para os empregos, para o bom casamento, para o prestígio social e político".

A atenção chamada pelos elementos acima permite retomar duas hipóteses que serviram de fio ao longo da realização da pesquisa que deu origem a este trabalho. A primeira delas diz respeito ao caráter peculiar da instituição militar brasileira, resultado da condição periférica do país no qual se desenvolveu; portanto, de ela ser parte de uma série de produtos importados ${ }^{4}$. A segunda hipótese, estreitamente relacionada à anterior, refere-se à inexistência - no período enfocado - de uma estrutura social cujo principal princípio de hierarquização encontre-se na profissão, logo, que permita que um título profissional funcione como garantia central de acesso a uma determinada posição na hierarquia social.

A começar pela instalação de uma corte imperial - fruto de uma história muito particular vivenciada por parte da Europa -, e de toda uma série de instituições (também no sentido de costumes, rituais e simbolismo) a ela inerentes, tais como ordenanças, milícias, ordens e títulos, mas igualmente códigos, doutrinas e filosofias, experienciou-se a implantação e utilização de produtos cujas condições de surgimento não encontraram paralelo no seio da sociedade importadora. Parte do aparato político-administrativo estatal, a instituição militar inevitavelmente incluía-se neste conjunto de estruturas e foi inicialmente rearranjada devido à extensão das terras coloniais. A impossibilidade de cobrir áreas muito grandes de terra fez com que as atividades militares das quais eram encarregados o exército e demais corpos portugueses recaíssem nas mãos de proprietários de terras locais.

Uma fraca institucionalização formal da competência militar propiciava, portanto, a coexistência de militares profissionais portugueses, proprietários privados, mercenários e ordenanças, tratando-se esses últimos de "milícias constituídas pelas câmaras locais, cujo princípio básico de organização hierárquica se dava a partir da nomeação estabelecida pelos senhores locais"

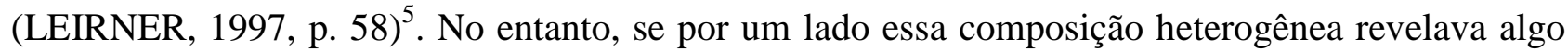
de inédito e específico - posto que não se tinha mais um exército colonizador original nem tampouco um aparato nativo -, por outro, mantinha uma estrutura hierárquica formal basicamente igual a dos exércitos originários do mundo feudal, isto é, assentava-se sobre patentes militares cujas posições equivaliam às "originais" e, inclusive, apresentavam uma nomenclatura praticamente idêntica àquelas ${ }^{6}$.

De tal situação compósita resultam sérias dificuldades para a apreensão de seus princípios estruturadores. Entretanto, mesmo que seja difícil demonstrar toda a complexidade envolvida nestes processos - o que implicaria tornar explícito, por meio de longa e minuciosa análise, as estratégias das elites importadoras e as respectivas lutas aí embutidas -, pretende-se lançar alguma luz sobre aspectos reveladores de seus efeitos na dinâmica do Exército brasileiro. Dentre esses, destacam-se a 
progressiva adoção de modelos europeus tanto de ensino técnico-teórico militar quanto de estrutura organizadora e a reelaboração dos princípios aí subjacentes (sobretudo os do "mérito") dentro de um novo contexto.

Nesse sentido, um ponto fundamental a ser retomado refere-se às tentativas de reformulação da instituição militar e de sua consequente "profissionalização". Como brevemente apontado, a criação da Real Academia Militar em 1810 tinha por finalidade "reformar o Exército e dar-lhe disciplina e instrução" (OLIVEIRA LIMA, p. 254, apud. MOTTA, op. cit., p. 13). Obra defendida por D. Rodrigo de Souza Coutinho (Conde de Linhares), Ministro dos Negócios Estrangeiros e da Guerra de D. João VI, refletia essencialmente preocupação em preparar comandantes aptos e engenheiros capazes de realizar obras na colônia, indo assim de encontro "à tradição portuguesa de incúria e imprevidência no que se refere ao preparo de soldados de seus exércitos" (MOTTA, op. cit., p. 14). Tratando-se de conferir "qualificação técnica" à instituição, buscaram-se nas práticas dos exércitos modernos da Europa os subsídios que formariam a base do ensino na Academia. Nesse caso, o modelo de ensino importado teria origem na França, principal paradigma militar naquele continente. Como é destacado, ainda que o domínio econômico e político se achasse em Londres, "nesse plano [das ideias], era em Paris que se procurava a inspiração e as regras. Os estudos de matemática, de engenharia e de técnica militar, a serem montados na Academia, iriam assentar, pois, sobre o pensamento e o didatismo francês" (Id., ibid., p. 31).

A introdução e ênfase estrita dadas às ciências exatas ${ }^{7}$ implicaram o surgimento de uma realidade nova e ambígua no interior do Exército. De um lado, surgia uma linha "teórica", centrada no estudo acadêmico de disciplinas "científicas" baseadas na matemática, desconectada de uma aplicação propriamente militar do conhecimento e em contraposição a uma tradição humanísticoliterária muito sedimentada. De outro, colocava-se a realidade das experiências de guerra, em especial no Rio Grande do Sul, e a necessidade de aplicação prática de princípios militares em situações que demandavam ações concretas. Em suma, a "vida acadêmica" e a "vida militar" andavam em linhas paralelas, característica que permaneceria intacta pelo menos até meados do século. Como escreve Motta (op. cit., p. 36),

no Largo de S. Francisco (Real Academia) falava-se em Frederico, Napoleão, Vaubam, enquanto na campanha riograndense (sic) os nomes eram Joaquim Xavier Curado, José de Abreu, Marques de Souza, Osório. Os nossos doutores, ou melhor, os nossos doutos, viviam em função dos problemas e das soluções de outros povos, e a ciência, neles, era sempre um fator de alienação e fuga. Isto na política, nas letras, nas cátedras, e no campo militar também. Por isso aqueles dois ensinos eram dois mundos que se ignoravam, fluíam em tempos históricos diferentes, distantes um do outro. 
E era em torno dessas linhas que se travavam as lutas pela própria definição legítima do "ser militar", traduzida nos termos da disputa entre "teoria" e "prática", escola para "soldados" ou escola para "doutores", entre "científicos" e "tarimbeiros". Reflexos desse embate foram as sucessivas modificações regulamentares sofridas pela Academia, todas elas fazendo oscilar o ensino ora em direção mais "militarista", defendida, sobretudo, por aqueles líderes militares cujas trajetórias estavam mais estreitamente ligadas à "carreira" propriamente dita; ora em sentido contrário, mais "academicista" e representada pelo corpo de lentes (professorado), defensores irredutíveis das disciplinas "científicas" e, próximos, assim, do ensino "civil"8.

Para citar um aspecto marcante do que foi referido, tem-se na reforma de 1839 uma primeira contrapartida às frustrações da Academia em relação a seus objetivos iniciais. Novamente voltandose para a França, tomou-se por modelo a Escola Técnica e a de Aplicação daquele país. Como o sistema francês supunha o desdobramento da formação do oficial em duas escolas, algo indesejado no momento, o resultado de sua adoção foi uma simbiose - do qual a mudança do nome de Academia para Escola Militar e a valorização do ensino técnico-profissional concomitante ao de matemática e de ciências eram indicativos -, como faz ver essa passagem extraída de um relatório elaborado pela comissão encarregada de criar o novo regulamento:

Tomamos por norma dos nossos trabalhos os programas das Escolas Politécnica e de Metz [França], como nos foi recomendado; mas apenas podemos imitá-los quanto ao espírito que neles domina, pela razão de que, podendo considerar-se a escola brasileira como uma fusão de ambas aquelas, era seu mister modificá-los quase na totalidade das suas disposições (Arquivo Nacional, caixa 694, 1849, apud. Motta, op. cit., p. 75, grifos nossos).

Símbolo expressivo dessa condição amalgamada, o surgimento da figura do "militar-bacharel" ou "militar-doutor"9 , em 1844, e de todas as possibilidades de uso social abertas pela detenção daqueles títulos, vêm a fortalecer a ideia de inexistência de uma estrutura militar pautada por regras próprias à profíssão no período. Ou seja, a indefinição de critérios estritos de entrada e de ascensão na carreira - predominavam, até então, basicamente critérios personalistas e adscritivos (ligações com o poder central, origem nobre) e o estudo não era condição, nem mesmo formal, necessária ao ingresso no oficialato -, implicava a subordinação da lógica institucional militar a outras que não as estritamente ligadas à profissão. De tal situação, em que a utilização de recursos diversos, notadamente o estabelecimento de relações com o imperador e seus círculos mais próximos e o envolvimento na "política civil" (SCHULZ, 1994, p. 23-33), permitia a ocupação de postos de comando e ao mesmo tempo a inserção em outras esferas de atividade, como a prática política, resultavam sérias dificuldades para a institucionalização do Exército em termos racionais ${ }^{10}$.

Ao seguir a tendência de tentativa de estruturação da profissão de oficial militar como uma carreira regida por conjunto de regras universais nos moldes considerados modernos, o Exército 
brasileiro continuaria a incorporar ao longo do século XIX, e, sobretudo, nas primeiras décadas do século seguinte, alguns traços dos principais esquemas organizativos desenvolvidos pelas corporações europeias. Em larga medida, a experiência bélica adquirida no conflito com o Paraguai revelara o despreparo tanto organizacional quanto material e técnico das tropas imperiais, o que estimulou uma reavaliação das condições gerais de sua organização, incluindo a participação de jovens oficiais de baixa e média patentes que passaram a se manifestar sobre aquele assunto a partir da fundação da Revista do Exército Brasileiro, em 1882.

Quanto à formação dos oficiais nas escolas militares, permaneceriam as oscilações entre um pólo "profissional-prático" e outro dito "científico", isto é, mantinha-se central a questão de determinar um quantum de "cultura geral" necessário ao preparo do profissional do Exército (MOTTA, op. cit., p. 210). Como indica McCann (1984, p. 751 e 2009, p. 102-254 e passim), somente entre os anos de 1889 e 1913, além de o governo ter gasto grandes quantias em duas reorganizações gerais e algumas outras parciais da instituição, "os regulamentos das escolas militares foram reescritos quatro vezes (duas dando maior importância à teoria sobre a prática e duas no sentido inverso)", os regulamentos das várias armas também sofreram diversas modificações e "os uniformes pareciam mudar de acordo com os ventos da moda". Com a proclamação da República, a reforma curricular de Benjamin Constant fez mais uma vez as orientações penderem no sentido de um teorismo baseado no ensino abstrato da matemática e das ciências exatas, fato que não era seguido pelas escolas práticas e de guerra, onde os exercícios aplicados ganhavam maior destaque. Juntamente com a queda da monarquia e a ascensão dos militares ao primeiro plano da política nacional, surgiram manifestações cujo conteúdo girava basicamente em torno da demanda pelo aumento de efetivos, por uma modernização estrutural e ainda pela aquisição de equipamentos.

As primeiras medidas mais efetivas começaram a tomar forma entre 1908 e 1914, com a instituição do serviço militar obrigatório, a criação dos Tiros de Guerra ${ }^{11}$ e de grandes unidades chamadas Brigadas Estratégicas, e também com a constituição e envio de uma turma de oficiais estagiários à Alemanha (LEIRNER, op. cit., p. 68; McCann, 2009, p. 214-253). De retorno ao Brasil, após contato direto com um dos reconhecidos modelos de exército na Europa, esse grupo de oficiais, apelidado em seguida de jovens turcos e autointitulado Cavaleiros da Ideia, fundaria o periódico militar A Defesa Nacional, primeiro instrumento de divulgação de um "pensamento militar enquanto um pensamento nacional" (Id., ibid., p. 69).

No entanto, o ponto mais alto nessa sequência de modificações organizacionais seria conhecido com a contratação de uma Missão Militar composta por oficiais franceses em 1919, a qual ficaria encarregada de operar uma reestruturação geral na organização do comando militar em conjunto com uma reformulação no sistema de ensino. Com respeito aos aspectos organizacionais, 
os resultados mais visíveis traduziram-se na constituição de um Estado-Maior efetivo ${ }^{12}$, centralizador do comando nacional do Exército e encarregado de elaborar as grandes diretrizes a serem aplicadas à totalidade da instituição, buscando, assim, romper os vínculos historicamente estabelecidos e mantidos entre setores do oficialato e elites regionais. Mais do que isso, de acordo com o papel desempenhado por aquele órgão na estrutura militar europeia, tratava-se de conformar uma esfera que comportasse oficiais especializados na arte da guerra e que, portanto, desfrutasse de relativa autonomia frente ao domínio da "política" naquilo que tocasse às orientações da política especificamente militar.

Quanto às alterações no sistema de ensino, de par com uma nova retomada dos estudos orientados preferencialmente ao emprego de conhecimentos teóricos em exercícios de caráter prático, trabalho comandado pelos instrutores, procurou-se acentuar sobremodo uma formação contínua do oficial militar ao longo da carreira. Para tanto, concebeu-se um sistema escolar diferenciado e diversificado, capaz de fornecer qualificação desde o nível preparatório ao ingresso no oficialato até os quadros destinados a compor o Estado-Maior do Exército e outros altos postos da hierarquia ${ }^{13}$. Como forma de regulação do acesso ao generalato, por meio de um decreto baixado em janeiro de 1919, decidiu-se que a partir do ano de 1929 ele passaria a estar condicionado à detenção indispensável do Curso de Estado-Maior.

\section{O cadetismo à brasileira: passaporte para altos escalões}

Provavelmente um dos aspectos mais reveladores da dinâmica específica, à qual estava submetido o Exército brasileiro ao longo do século XIX, seja a instituição do cadetismo. Introduzido em Portugal em 1757, o título de cadete conferia aos filhos da nobreza o direito a ingressar na carreira das armas com a honra de oficiais, abrindo-lhes assim privilégios negados a outros grupos sociais. Transplantado para o Brasil, sofreu modificações significativas em seu conteúdo e usos. Originalmente destinado àqueles jovens que tivessem comprovada sua ascendência nobre, o título de cadete rapidamente passou a ser alvo de camadas menos restritas da população.

Desse modo, ao lado do título de primeiro cadete, destinado aos filhos de nobres e de oficiais superiores, surgiram também os de segundo cadete e de soldado particular, os quais teriam igualmente ampliadas suas concessões. Em 1853, o direito a ser reconhecido cadete foi estendido aos filhos de oficiais da Guarda Nacional ( $1^{\circ}$ cadete para os filhos de oficiais superiores e $2^{\circ}$ cadete para os filhos de oficiais subalternos), e em 1879 poderiam tornar-se soldados particulares os filhos de "doutores em medicina, que, mesmo se rotulados plebeus ex hypothesis, gozavam de consideração civil na sociedade, pelo galardão científico e pela profissão exercida" (CUNHA, 1966, p. 37). O mesmo passava a ser aplicado aos filhos dos bacharéis formados em Ciências Jurídicas e Sociais, ou Físicas, Naturais e Matemáticas (CIDADE, 1961; CUNHA, op. cit.). 
Em questão de algumas décadas, como se nota, o cadetismo à brasileira transformara-se em algo bastante distinto da instituição portuguesa, cuja função essencial era abrir às camadas nobres acesso privilegiado aos altos postos militares, garantindo, desta forma, a reprodução restrita de uma "elite corporativa das armas". No caso do Brasil, em um contexto de disputa de grupos sociais por espaços e carreiras mais seguros ofertados pela expansão das estruturas burocráticas (Exército, Guarda Nacional e Igreja, sobretudo), sua adaptação teve efeitos diversos e veio a ampliar largamente a possibilidade de uma "boa entrada" na carreira das armas ${ }^{14}$. Vale dizer, na medida em que eram postos de lado os critérios de nobreza de filiação como única condição de acesso ao título, e substituídos por outros, menos rígidos, tais como "ser filho de oficial", "ter um pai de profissão 'reconhecida'" ou, ainda, simplesmente "possuir determinados bens", passava-se necessariamente a modificar os mecanismos de regulação da carreira no Exército.

Se essas modificações nos critérios de reconhecimento do direito ao título eliminavam o exclusivismo da nobreza - fazendo diminuir o número de oficiais europeus no seio da instituição ${ }^{15}$-, ao mesmo tempo colocavam em evidência uma dimensão fundamental da dinâmica social vigente, que era a utilização de relações baseadas no capital social e simbólico como requisito para a aquisição de trunfos sociais diversos (CORADINI, 1995 e 1998). Assim, o estabelecimento e uso de relações não somente com o poder central, em um contexto de acentuado patrimonialismo, mas também com os poderes regional e local, através de ligações partidárias, de parentesco, compadrio e amizade, ou ainda da sobreposição dessas, pautava em larga medida a lógica do cadetismo $^{16}$. Tipicamente exemplar do que se expõe é o caso do marechal Setembrino de Carvalho (1861-1947), o qual, quando ainda aluno da Escola Militar de Porto Alegre e almejando ser reconhecido cadete o que lhe garantiria vantagens inegáveis na carreira -, procura pessoalmente o Presidente da província e lhe expõe seu "problema". Este, ao saber que se tratava do filho de um "importante correligionário", seu "conhecido", imediatamente assina a nomeação do pai como coronel da Guarda Nacional em Uruguaiana, assim permitindo a Setembrino obter a demanda desejada (CARVALHO, 1950, p. 24-25; SEIDL, 2008).

Como se percebe, a extensão do título de $1^{\circ}$ ou $2^{\circ}$ cadete aos filhos de oficiais da Guarda e o de soldado particular também aos filhos de burocratas, "doutores" e proprietários permitia o recrutamento privilegiado de oficiais com base agora não apenas em critérios como "tradição militar familiar" e "fidalguia". Em acordo com o contexto e a estruturação social vigentes no período, recursos como a posse de algum patrimônio econômico, de determinados "títulos" ("doutor", "bacharel") e, sobretudo, a detenção de uma rede relativamente extensa de relações, incluindo agentes próximos às esferas do poder político e da burocracia imperial, ampliavam o horizonte de postos, davam estabilidade e prestígio às novas frações sociais candidatas a grupos dirigentes ${ }^{17}$. 


\section{Oficialato: uma questão de mérito?}

Dentre os efeitos advindos com a reforma de 1850 estavam o desdobramento da Escola Militar (antiga Academia Real) em duas (uma permaneceria no Largo de São Francisco e a outra iria para a Fortaleza de São João, e após, para a Praia Vermelha, em 1857), e a criação do Curso de Infantaria e Cavalaria, em Porto Alegre. Além disso, a rede escolar seria também ampliada com a criação, em 1859, da Escola de Tiro de Campo Grande, e a inclusão dos estudos "preparatórios" (secundários) no currículo da Escola Militar, em 1858. Esse último aspecto traduzia um crescente interesse do Exército em fornecer ensino secundário aos filhos de militares, ao mesmo tempo oferecendo oportunidade de estudo àqueles com poucas chances de realizá-lo em outra instituição, e preparando parte daqueles que continuariam seus estudos nos cursos superiores. Gradativamente expandindo seu sistema escolar autônomo, o Exército elaborava mecanismos de reprodução cujas regras formais oficialmente apresentadas repousavam cada vez menos sobre critérios personalistas e informais e passavam a depender mais estreitamente de sua relação com uma estrutura formal de legitimação social.

Assim, iniciada em meados do século XIX, a tendência à modernização do Exército continuou a se afirmar ao longo do Império e ganhou impulso especial nas primeiras décadas da República: criação de novos cursos, envio de oficiais estagiários e de comissões militares ao exterior (Alemanha), vinda da Missão Militar Francesa (1919-1940) ${ }^{18}$. Em linhas gerais, apontava-se para um sistema de promoções bem definido - no qual o "mérito por estudo" torna-se via central à ascensão -, combinado com a adoção de estruturas organizacionais de competências específicas e com a aquisição de aparelhamento técnico-bélico condizente com o estado da arte da guerra moderna. Por outro lado, ainda que grande parte do acima referido seja verdadeiro, sobretudo com respeito à difusão do ensino e da adoção de instâncias mais formalizadas de organização, devem ser examinadas com cautela as diferenças e as relações entre as regras formais apresentadas pela instituição militar (sistema de ensino, leis, regulamentos etc.) e as regras objetivas - mecanismos não-formais e lógicas de ação - que concretamente regulavam a carreira no período, sobretudo nos níveis mais altos da hierarquia.

Nesse ponto, caberia em especial introduzir uma discussão acerca da noção de "mérito", amplamente difundida nos trabalhos historiográficos dedicados ao Exército brasileiro. Tal noção lhes tem servido como ponto de referência para indicar a adoção de um princípio teoricamente universal, igualitário e impessoal como mecanismo principal de acesso aos postos mais elevados da hierarquia militar.

Como já mencionado diversas vezes, a literatura afim tem encontrado no "mérito" lugar de acordo indiscutível para demonstrar de que modo se deu a ruptura entre o padrão de recrutamento da oficialidade do Exército antes e depois da metade do século XIX. Com efeito, os trabalhos de 
John Schulz (1994) e de José Murilo de Carvalho (1977), primeiros a apresentar dados concretos sobre a composição do oficialato ao longo do Império e da Primeira República, tornaram-se referenciais para pesquisas posteriores. Utilizando grande quantidade de indicadores tais como profissão dos pais dos generais, origem geográfica, posse ou não de curso superior, idade de ascensão ao generalato e vários outros, relacionam a redução do que chamam de "elite" na composição do alto oficialato à "abertura da carreira ao talento"19; ou seja, à possibilidade de entrada e ascensão na hierarquia de pessoas de baixa extração social, favorecidos pelo caminho oferecido pelos estudos e pela "dedicação" à carreira.

Duas considerações importantes merecem ser feitas com relação aos pressupostos subjacentes a essa abordagem. Em primeiro lugar, ao se utilizar a noção de "mérito" como recurso acessível a todos que se dispusessem a aceitá-lo como tal ao ingressar na carreira militar ("o 'esforço', o 'trabalho', a 'disciplina' enfim, a 'dedicação à carreira' terá como 'recompensa' a ascensão na hierarquia"), são desconsiderados todos os efeitos de seleção e classificação sociais operados pela escola e pela instituição militar ela mesma, as quais, como se sabe, são inseparáveis de suas lógicas sociais (BOURDIEU, 1989; BOURDIEU; PASSERON, 1992; BOURDIEU; SAINT MARTIN, 1987). Em outras palavras, ao apontar o "mérito" (ou o "talento", agora não mais em um sentido de "qualidades herdadas", "adscritivas", próprias à "nobreza") como "valor em si", "critério justo" de ascensão e acesso a posições dominantes, a análise compactua com uma visão que é própria da ideologia escolar e deixa, assim, de tentar capturar as relações objetivas entre as instituições escolar e militar e a estrutura social. Isto é, impede-se de serem explicitadas as formas pelas quais aquelas instituições, especialmente a escola, transformam hierarquias sociais em hierarquias escolares ${ }^{20}$ (e também militares ou profissionais), cumprindo papel fundamental na manutenção da ordem social (PINTO, 1996, p. 23-35).

Em segundo lugar, é necessário chamar atenção para o fato de o próprio termo mérito, assim como outros também componentes da "ideologia meritocrática", ser uma categoria importada. Logo, suas condições históricas de surgimento e de uso, seu ethos e regras próprias nunca podem ser transplantados sem sofrerem modificações. Falar, pois, em uma "ideologia do mérito" no Brasil imperial resulta, no mínimo, em referência a algo muito diverso do fenômeno observado em especial na França pós-revolucionária, em que a meritocracia gradativamente impõe-se como principal (mas não único) princípio de legitimação social da burguesia emergente (CHARLE, 1987, p. 36-72; CHAUSSINAND-NOGARET, 1991, p. 217-315).

Não desconsiderando as mudanças concretas operadas no interior do Exército brasileiro, principalmente quanto ao aumento expressivo no nível de escolarização militar do oficialato ${ }^{21}$ e de uma tendência marcante ao recrutamento endógeno de sua elite, parece-nos imprescindível proceder a uma relativização das conclusões tradicionalmente apresentadas. Tal procedimento tem por base, 
além do que foi exposto, a premissa de que, pelo menos para o período em estudo, não se tem no Brasil uma estruturação social na qual o principal princípio de hierarquização e de classificação social esteja baseado na profissão (CORADINI, 1995 e 1998), logo, que a aquisição de um título escolar tenda a garantir o acesso a uma posição correspondente na hierarquia social. Por outro lado, ainda que o título tenha se tornado cada vez mais um trunfo indispensável para a ocupação de posições dominantes, em particular no caso de uma corporação como o Exército, restam a ser analisados com detalhes, em primeiro lugar, as propriedades sociais dos agentes em questão e, em segundo lugar, os possíveis usos sociais dos títulos obtidos.

Ao se examinar as origens sociais dos generais do Exército brasileiro no período 1822-1930 (quadro I), fica patente a manutenção de um recrutamento social realizado predominantemente entre filhos de oficiais e de indivíduos oriundos de frações sociais favorecidas (“doutores”, grandes e médios proprietários de terras, funcionários de alto e médio escalões). Tomados globalmente no período, 83,37\% dos generais brasileiros eram, eles próprios, filhos de oficiais militares, seguramente um dos maiores índices de endogenia dentro dos grupos dirigentes brasileiros até o final da Primeira República. Tais dados confirmam o que é assinalado de forma unânime pela bibliografia como uma oficialidade essencialmente "aristocrática" e próxima da órbita estatal até meados do século XIX. Ocorre que os indicadores mostram que esse padrão não se modifica significativamente na segunda metade daquele século, após a série de reformas.

Quadro I: Generais brasileiros - profissão do pai

\begin{tabular}{|l|c|c|c|}
\hline Profissão/Período & $1822-1860$ & $1861-1889$ & $1890-1930$ \\
\hline Oficial Superior & $41(59,42 \%)$ & $33(66,00 \%)$ & $50(34,24 \%)$ \\
\hline Oficial Subalterno & $06(8,69 \%)$ & $09(18,00 \%)$ & $63(43,15 \%)$ \\
\hline Doutor & $04(5,79 \%)$ & 00 & $13(8,90 \%)$ \\
\hline Proprietário & $01(1,44 \%)$ & $01(2,00 \%)$ & $03(2,05 \%)$ \\
\hline Funcionário Público & 00 & 00 & $02(1,36 \%)$ \\
\hline Dout./Prop./Func. Púb. & 00 & $03(6,00 \%)$ & $10(6,84 \%)$ \\
\hline Desembargador & $04(5,79 \%)$ & 00 & 00 \\
\hline Conselheiro & $01(1,44 \%)$ & 00 & $02(1,36 \%)$ \\
\hline Negociante & $01(1,44 \%)$ & 00 & 00 \\
\hline Diplomata & 00 & 00 & $01(0,68 \%)$ \\
\hline Médico do Exército & 00 & 00 & $01(0,68 \%)$ \\
\hline Oficial Militar* & $11(15,94 \%)$ & $02(4,00 \%)$ & $01(0,68 \%)$ \\
\hline Outras & 00 & $02(4,00 \%)$ & 00 \\
\hline Total generais & 122 & 68 & 220 \\
\hline Total conhecido & $69(56,55 \%)$ & $50(73,52 \%)$ & $1466,36 \%)$ \\
\hline
\end{tabular}

FONTE: Informação fornecida pela patente de cadete apresentada pelo filho, sem maior especificação de sua qualidade. Fonte: Silva, 1940; Lago, 1942; Fés-de-Ofício; Processos de Reconhecimento de Cadetes, AHEx, RJ; material diverso reunido pelo autor.

Pelo contrário, os dados relativos ao período 1861-1889 apontam manutenção daquele quadro e mostram ligeira elevação no número de filhos de oficiais $(88,00 \%)$, dos quais cerca de dois terços 
eram filhos de oficiais superiores. Ora, considerando-se que esse intervalo de tempo cobre precisamente a época apontada como de "abertura" da carreira militar ao talento, ficam interrogações quanto aos efeitos concretos da introdução oficial da lógica meritocrática e de que forma o sistema escolar funcionava na seleção dos quadros dirigentes da instituição. E mais, como conjugar isso com a manutenção do cadetismo, encarnação do privilégio social por excelência e bilhete de entrada "por cima" no Exército, até o final do Império?

Por outro lado, é a inversão na proporção de filhos de oficiais superiores $(34,24 \%)$ e subalternos $(43,15 \%)$ entre o generalato brasileiro das quatro primeiras décadas da República que sugere o estabelecimento de condições de carreira mais palpáveis a agentes menos dotados em termos de capital econômico, social e simbólico ${ }^{22}$. Embora tudo indique, de fato, que o Exército cada vez mais abrisse espaço em sua alta esfera a agentes, cujos principais trunfos iniciais fossem o investimento escolar e a obediência à disciplina institucional, não se pode perder de vista outros determinantes de carreira que se combinavam com a lógica escolar ou meritocrática e compunham, de modo objetivo, os destinos profissionais dos futuros dirigentes.

Quadro II: Generais gaúchos - profissão do pai

\begin{tabular}{|l|c|c|c|}
\hline & & & \\
Profissão/Período & $1822-1853$ & $1854-1889$ & $1890-1930$ \\
\hline Oficial Superior & $08(88,89 \%)$ & $08(80,00 \%)$ & $23(48,93 \%)$ \\
\hline Oficial Subalterno & 00 & 00 & $14(29,78 \%)$ \\
\hline Doutor & $01(11,11 \%)$ & 00 & 00 \\
\hline Proprietário & 00 & $02(20,00 \%)$ & $02(4,25 \%)$ \\
\hline Funcionário Público & 00 & 00 & $02(4,25 \%)$ \\
\hline Dout./Prop./Func. Púb. & 00 & 00 & $05(10,63 \%)$ \\
\hline Médico do Exército & 00 & 00 & $01(2,12 \%)$ \\
\hline Total generais & 12 & 13 & 54 \\
\hline Total conhecido & $09(75,00 \%)$ & $10(76,92 \%)$ & $47(87,03 \%)$ \\
\hline
\end{tabular}

FONTE: Silva, 1940; Lago, 1942; Fés-de-Ofício; Processos de Reconhecimento de Cadetes, Arquivo Histórico do Exército, RJ; material diverso reunido pelo autor.

Quadro III: Generais gaúchos - patente dos oficiais militares pais de generais

\begin{tabular}{|l|c|c|c|}
\hline & & & \\
Patente/Período & $1822-1853$ & $1854-1889$ & $1890-1930$ \\
\hline General & $04(50,00 \%)$ & $03(37,50 \%)$ & $10(27,02 \%)$ \\
\hline Coronel & $01(12,50 \%)$ & $01(12,50 \%)$ & $03(8,10 \%)$ \\
\hline Tenente-Coronel & $02(25,00)$ & $02(25,00 \%)$ & $02(5,40 \%)$ \\
\hline Major & 00 & 00 & $06(16,21 \%)$ \\
\hline Capitão & 00 & 00 & $01(2,70 \%)$ \\
\hline Tenente & 00 & 00 & $04(10,81 \%)$ \\
\hline Alferes & 00 & 00 & $02(5,40 \%)$ \\
\hline Superior (não especificada) & $01(12,50 \%)$ & $02(25,00 \%)$ & $02(5,40 \%)$ \\
\hline Subalterno (não especificada) & 00 & 00 & $07(18,91 \%)$ \\
\hline Total & 08 & 08 & 37 \\
\hline
\end{tabular}

FONTE: Silva, 1942; Lago, 1940; Fés-de-Ofício, AHEx, RJ; Material diverso reunido pelo autor. 
Caberia, assim, abordar a questão das intersecções entre o espaço militar e o espaço da política ou, mais especificamente, das representações dos oficiais militares sobre o fenômeno político e as respectivas tomadas de posição que alguns deles lograram expressar com maior intensidade e reconverter em trunfos profissionais.

\section{Militares e intelectuais: duas vocações?}

Como demonstrado em outros trabalhos (SEIDL, 2002; 2008), a participação direta ou indireta de oficiais do Exército no universo da política - seja em partidos, movimentos ou apenas através de ligações pessoais mais ou menos explícitas com agentes detentores de recursos políticos , constituiu traço estruturante da carreira de oficial militar até as primeiras décadas da República ao ocupar espaço importante nas engrenagens de regulação da ascensão na hierarquia.

Se desde o período colonial até pelo menos o final do Império fora bastante significativa a presença de oficiais graduados na ocupação de altos cargos políticos (deputado, senador, ministro, presidente de província) e da burocracia administrativa ${ }^{23}$, a redução conhecida nas primeiras décadas seguintes não traduziu propriamente uma diminuição na intensidade daquele tipo de envolvimento, mas uma mudança em sua forma. O surgimento dos movimentos republicanista e abolicionista que marcariam as últimas décadas do regime imperial seria largamente incorporado pelo ideário de boa parte do oficialato do Exército brasileiro, o qual após seu último grande conflito no Paraguai desenvolvera maior sentimento de unidade corporativa, de sua importância para o país e ao mesmo tempo de frustração frente ao bacharelismo civil (SCHULZ, 1971, p. 252).

A percepção de uma progressiva perda de importância social do oficialato durante o Império, que ia de par com a ascensão política de frações sociais cada vez mais legitimadas pela apresentação de um título de bacharel em Direito, mas que também se associava a certo descaso do governo central em relação à corporação (criação da Guarda Nacional, redução de quadros e de verbas), entraria por uma boa parte nas razões que levariam uma fração do oficialato a reivindicar a substituição dos valores vigentes naquele regime.

Ao lado disso, há de se considerar, sem, no entanto, exagerar em sua importância, a influência das adaptações da doutrina positivista sobretudo nos meios militares mais intelectualizados, isto é, nas escolas preparatórias de oficiais, e sua relação com determinados ideais republicanos e com o conjunto das representações do mundo social que tinham aqueles militares ${ }^{24}$. Conforme mostra Castro (1995, p. 63-84) com respeito ao ambiente intelectual na Escola Militar da Praia Vermelha, a incorporação pelos alunos e jovens oficiais militares daquilo que se chamava de positivismo - mas que não se restringia aos escritos do filósofo francês, agregando vários outros pensadores evolucionistas -, devia-se em primeiro lugar à importância que aquelas ideias atribuíam à matemática e às ciências; em segundo lugar, "pela oposição tenaz ao espírito legista encarnado 
idealmente pelos bacharéis em direito"; e em terceiro, "pelo lugar de destaque reservado à nova elite 'científica' no estágio positivo que se avizinhava" (Ibid., p. 67). Essas influências, vindas do Rio de Janeiro e introduzidas por alguns professores, também tiveram expressão na Escola Militar de Porto Alegre, que no período de 1874 a 1889 serviu como foco de difusão da propaganda republicana na região, chegando a abrigar em 1883 um clube (Federação) voltado para aqueles fins (MEDEIROS, 1992, p. 54-55) ${ }^{25}$. Como mostra Ferreira (1975, p. 121), por essa época a Escola havia se constituído, "a exemplo das faculdades de Direito de São Paulo e Recife e da Escola Central da Corte, em núcleo de fermentação cultural e irradiação de ideias", função que cumpriu "nos mais variados setores da vida mental, política e social do Rio Grande do Sul".

Outro índice significativo dessa interpenetração entre o mundo da oficialidade militar e as questões de ordem da agenda política e social que se colocavam à época é igualmente percebido na criação, também por oficiais da Escola Militar de Porto Alegre, da Sociedade Científica e Literária Culto às Letras, cujo porta-voz era a Revista Mensal (1880). Através de publicações de textos ensaísticos, traduções e poesias, seus membros propunham, como demonstra a apresentação em seu primeiro número, abordar, "à luz das ideias do "progresso" e da "razão científica", os "grandes temas" que se faziam presentes nas "sociedades modernas":

Ao transpor o limiar da vasta arena, onde se debatem as grandes ideias filosóficas do século, em que a mentalidade positiva, num progressivo desenvolvimento, simboliza a síntese da atividade racional, na vasta escala dos conhecimentos, a Revista da Sociedade Literária e Científica Culto às Letras, sente que lhe falecem as forças ante a enormidade da luta que se trava entre o espírito filosófico dominante da época e os anacronismos teológicos que ainda infelizmente medram nas sociedades modernas.

Ela representa no grande mundo jornalístico do nosso país um tentame na cruzada empreendida pelos representantes do progresso e da civilização hodiernos; é apenas um minguado produto dos esforços duma pequena fração da mocidade acadêmica brasileira que, inspirando-se nas ideias regeneradoras dos grandes mestres, vem contribuir, [...], para a propagação das luzes que se refletem no grande prisma da ciência universal, cujas múltiplas faces são os grandes atletas da Razão e da Ciência (Apud. Ferreira, op. cit., p. 117-118, grifos no original).

Sem citar em sequer uma passagem suas condições de oficiais ou mesmo fazer qualquer referência ao Exército, tais militares identificavam-se como parte da "mocidade acadêmica brasileira", ou seja, como intelectuais que tratavam de temas amplos e demonstravam apreço por uma "cultura erudita" baseada na "filosofia", nas "ciências" e na "literatura". Integrando uma camada reduzida de pessoas com acesso à educação formal e à cultura letrada, ao evocar tais temáticas, pelo prisma da "razão", e se expressar por vocabulário reconhecido e valorizado como saber social por amplos setores da sociedade (PÉCAUT, 1990, p. 33), propunham estar totalmente de acordo com o "espírito da época", vindo a atingir grande notoriedade não apenas no âmbito regional como também em nível nacional (FERREIRA, op. cit., p. 125). Essa extrapolação dos 
limites do ofício de militar, dispondo-os a "pensar cientificamente" todo o social, serviria de subsídio a um envolvimento mais efetivo na arena política.

Também a introdução de certo positivismo nas escolas militares, e em particular na Escola Militar de Porto Alegre, teria papel importante como elo entre uma fração mais escolarizada do oficialato e uma série de manifestações político-ideológicas cujo conteúdo principal giraria basicamente em torno da abolição do regime escravocrata e da noção de república, representando, sobretudo, uma mudança nas elites políticas imperiais. Porém, da mesma forma, ligaria com maior intensidade parte dessa oficialidade ao Partido Republicano de Júlio de Castilhos e levaria muitos oficiais a tomar parte na fundação de clubes e centros de propaganda republicana por toda a província do Rio Grande do $\mathrm{Sul}^{26}$. Em alguns casos, como o do futuro marechal, deputado estadual e governador do Ceará Setembrino de Carvalho (1861-1947), ocorreriam implicações diretas na disputa política (CARVALHO, 1950; SEIDL, 2008).

Bem ajustado às aspirações de um grupo às voltas com reconhecimento e poder, os discursos sobre a crença num progresso baseado na ciência, sustentada principalmente por um ensino teórico voltado à formação de engenheiros militares e de bacharéis em ciências físicas e naturais, forneceriam bons instrumentos para um engajamento militar que punha sua ação em nome de um conjunto de princípios "modernizadores". Mais do que uma troca de regime político, o republicanismo que defendiam continha uma noção de modernização que se estendia desde a necessidade da construção de ferrovias, portos e meios de comunicação em geral até a abolição da escravidão e a mudança nas elites políticas, incluindo uma regeneração moral da sociedade (sobretudo, o fim do nepotismo) (MCCANN, 2009, p. 214-253 e passim; SCHULZ, op. cit., p. 254). Ao se colocarem no mesmo plano que o restante da população civil, os oficiais defendiam a possibilidade de ter direitos políticos e sociais como qualquer outro cidadão. Ou ainda, conforme expressão de José Murilo de Carvalho (1977), a ideologia intervencionista do soldado cidadão propunha a participação dos militares tanto como forma de transformar sua posição social considerada subordinada quanto, numa versão mais radical, como prerrogativa da própria condição de militar, isto é, "cidadão" por excelência.

É a partir daí, por exemplo, que se pode entender melhor a reconversão de alguns oficiais, como Frederico Solón de Sampaio Ribeiro (futuro deputado federal e governador do Mato Grosso), em líderes e porta-vozes de causas tornadas comuns a civis e a militares. De fato, nesse momento não é possível perceber uma diferenciação que colocasse os militares como representantes exclusivos e legítimos de causas candentes como o abolicionismo e o republicanismo. As palavras de Solón em discurso na sessão oficial de inauguração da Confederação Abolicionista Paranaense deixam ver, além do próprio reconhecimento social do militar como agente legítimo, autorizado a 
falar sobre um determinado assunto do mundo social (no caso, a "questão da abolição"), também a forma como esse era elaborado e apresentado como interesse comum:

[...] A concepção que preocupa atenciosamente o espírito dos vultos mais adiantados da atualidade é de maior alcance porque afeta de frente os interesses gerais da humanidade, envolvendo particularmente os brios, a honra, e a liberdade de nossa Pátria: trata-se da abolição imediata dos escravizados no Brasil, cujo desenvolvimento moral e material depende exclusivamente da pronta solução de tão instante e grandioso problema, que acentuando-se de modo altamente eloquente no ânimo de quase todos os habitantes deste Império transformou-se em ardente aspiração nacional (Instituto Histórico e Geográfico Brasileiro, documento da coleção, sem data e referências, sublinhados no original).

Se o caráter mais "civilista" da primeira intervenção dos militares na política nacional durante as últimas décadas do Império parecia não traçar distinção clara entre a corporação e a população civil, unindo a todos sob a denominação genérica de cidadãos, o mesmo não seria válido para as propostas de tom militarista surgidas ao longo da República Velha. Naquelas ocasiões, a representação dos militares como "classe privilegiada", "naturalmente dotada" para assumir posição-chave no governo da nação, aparece explicitamente nas manifestações de seus líderes, dentre os quais destacou-se o oficial Jovem Turco ${ }^{27}$, futuro general e fundador da revista A Defesa Nacional Bertoldo Klinger (1884-1969).

A proclamação de uma "vocação militar para elite dirigente" - utilizando a expressão de Daniel Pécaut para os intelectuais brasileiros - estaria desta vez centrada na própria condição do "ser militar". Vale dizer, o que licenciaria legitimamente o oficialato militar a reclamar para si as tarefas de organização e administração do país era justamente o fato de a corporação reunir constitutivamente as qualidades fundamentais e indispensáveis, em sua visão, para o "bom governo público". Quando Klinger afirma que "a profissão militar é precisamente aquela que, intrinsicamente, maior aptidão cria no cidadão para o julgamento dos interesses coletivos nacionais e o exercício dos cargos diretores da política nacional" (1948, p. 379, grifos nossos), há toda uma concepção meritocrática da profissão de militar que se opõe aos "vícios" e "fraquezas" das frações dirigentes civis.

Por assentar-se formalmente sobre a disciplina hierárquica, o respeito à ordem e a regras válidas para todos - mesmo que em um paradoxo aparente Klinger e outros oficiais questionassem os mecanismos pouco claros e nada impessoais de regulação da carreira -, o sistema militar representaria o papel de formador de cidadãos especialmente capacitados em defender os "interesses nacionais", identificando ao mesmo tempo um mérito militar com um mérito social e a função do Exército com um imperativo nacional. Da mesma forma que se propugnava a preparação de oficiais profissionalmente qualificados (Klinger e os outros Jovens Turcos insistiram muito nesse ponto), também sustentava-se a legitimidade de sua intervenção na política. Porém, o sentido desta 
intervenção diferenciava-se daquele proposto pela ideologia do soldado-cidadão contido nos movimentos do final do século XIX e, de certa forma, nos levantes tenentistas.

Carvalho (1977, p. 213-214) chama atenção para o fato ao dizer que, enquanto os tenentes defendiam uma intervenção reformista, "a ser feita pelo militar independentemente, ou mesmo contra a organização", "Klinger propunha uma intervenção controladora ou 'moderadora', a ser levada a efeito pela organização como tal, orientada por seu órgão de cúpula, o estado-maior". Ou seja, de um lado, oficiais de baixas patentes sem perspectivas de alcançar graduações mais altas devido à estrutura organizacional do Exército que produzia gargalos de estrangulamento nos primeiros postos - e que punham em xeque o próprio sistema promocional; e de outro, oficiais bem posicionados na hierarquia, com claras aspirações aos postos de comando, sustentando o envolvimento mais efetivo de apenas uma parcela qualificada de membros da oficialidade. Note-se que estes últimos, ex-alunos dedicados, antes dos trintas anos de idade já haviam adquirido no exterior um tipo raro de expertise amplamente mobilizado nas batalhas internas à corporação.

Essa revelação de uma "vocação militar para a direção do país" não pode ser desvinculada, contudo, do contexto mais geral de desilusão com a República que começa a tomar forma e a ocupar espaço no universo social e cultural dos anos vinte. Os comentários de Pécaut (op. cit., p.2122) sobre as condições sociais em que os intelectuais brasileiros da época passaram a reivindicar uma posição de elite dirigente são reveladores das questões que estavam em jogo também para os militares:

Estavam [os intelectuais], acima de tudo, desiludidos com a República, não por ela ter arruinado a influência das oligarquias, mas, ao contrário, por ter permitido que essa influência se prolongasse indefinidamente no quadro das transições regionais. Aspirando à organização da nação pelo poder, reagiram contra a "oligarquização" das instituições. E sua politização não foi um pretexto para promover interesses próprios, mas, antes de tudo, expressava sua conversão à ação política.

No Brasil dos anos 20, os projetos dos intelectuais eram inseparáveis da vontade de contribuir para fundamentar o cultural e o político de uma forma diferente. Tudo estava em jogo ao mesmo tempo. Instituição alguma escapou à necessidade de assumir uma nova legitimidade: tanto a Igreja como o Exército, tanto o Estado como os estabelecimentos de ensino superior. A intervenção política dos intelectuais inseriu-se em uma conjuntura de recriação institucional (Id., ibid., p. 21-22).

A menção ao Exército é oportuna. De fato, tanto os tenentes quanto os oficiais moderadores incluíam em suas concepções a tarefa fundamental de redefinir a questão da legitimidade política. Para tanto, tinham de redefinir primeiramente a eles próprios. Ambos afirmavam, assim como o fizeram os intelectuais, sua presença como categoria socialmente desvinculada, portanto sem compromissos com nenhum outro interesse que aquele de toda a nação brasileira. No caso dos defensores da "intervenção moderadora", é ainda mais patente a semelhança entre as estratégias de 
militares e de intelectuais, pois também aqueles sustentavam a posse de um saber social legítimo fundado no "conhecimento profundo da nação" e voltado para a garantia de sua unidade.

O caráter de única instituição realmente presente em todo o território, aliado aos já mencionados aspectos peculiares à carreira militar profissional e supostamente conferidores de uma série de qualidades - dentre as quais a noção de patriotismo tinha grande importância -, era invocado como fundamento para o exercício pelo Exército (na verdade, somente por uma cúpula de oficiais) de um papel proeminente no controle dos desígnios da nação. A aplicação mais evidente desses recursos foi vista na articulação do golpe que depôs o presidente da República Washington Luís em 1930, realizado pelo Movimento Pacificador, cujo planejamento e execução couberam aos altos escalões do Exército e da Marinha. Como escreveu em suas memórias (compostas por sete volumes!) o general Bertoldo Klinger, então chefe do Estado-Maior das Forças Pacificadoras e redator da intimação que exigia a saída do presidente, havia chegado o momento de entregar os destinos do Brasil aos generais de terra e mar.

\section{Considerações finais:}

Ao tentar integrar num mesmo esforço de compreensão do Exército brasileiro perspectivas de caráter mais estrutural e análises centradas nas lógicas de ação de atores e de grupos concretos, cremos serem menores os riscos de adesão a visões evolucionistas e institucionalistas sobre aquela corporação. De um lado, a aposta numa abordagem que privilegia os efeitos dos processos de adaptação e readaptação tanto dos esquemas organizacionais quanto dos estoques de ideias ligados ao espaço da burocracia estatal brasileira favorece a compreensão da dinâmica própria adquirida pelas engrenagens do poder do estado e das disputas travadas em seu entorno.

Sem optar por explicações que oscilam entre tensões de classe e efeitos organizacionais para dar conta da formação do Exército nacional e, em especial, das intensas relações da instituição com a esfera da política, a análise esforçou-se em restituir parte da história social de uma corporação estatal na qual frações dos grupos dirigentes encontraram abrigo ao longo de muitas décadas. Excelente exemplo, a luta pela manutenção e expansão dos privilégios de acesso ao oficialato oferecido pelo cadetismo, evidencia a lógica dos arranjos organizacionais destinados a garantir carreiras relativamente seguras a membros de grupos em posições dominantes (em primeiro lugar aos próprios filhos de oficiais graduados e aos nobres civis, mas também a proprietários de terras e altos funcionários) e intermediárias (profissionais liberais e oficiais de médio escalão).

Visivelmente assentadas na ideologia do mérito, as constantes modificações no sistema escolar do Exército durante o século XIX estiveram, no entanto, atravessadas por mecanismos voltados à ascensão e reprodução de indivíduos, via de regra, oriundos de posições sociais mais privilegiadas. Embora pouco explorado nesse trabalho, é também fundamental lembrar o peso das 
relações pessoais e da série de estratégias ligadas a seu acúmulo, manutenção e acionamento na realização de carreiras ascendentes, sobretudo nas daqueles menos providos em dinheiro e prestígio familiar. O favoritismo, reclamado com base em amizade, parentesco ou afinidade política, passou longe da extinção e foi moeda corrente até, pelo menos, o final da República Velha. Ao mesmo tempo, contudo, a instituição via crescer o grau de profissionalização, domínio e interesse técnico de parte de seu alto oficialato, já menos tripulado por herdeiros de grandes famílias.

Os efeitos da chegada de indivíduos de origem menos elevada - mais dependentes de seu próprio esforço e do investimento na escola, mas, ressalte-se, nem sempre apenas disso - aos escalões de destaque na hierarquia podem ser percebidos, sobretudo, em tomadas de posição "técnicas", "neutras" e "profissionais", que procuram distanciar o ofício militar tanto do diletantismo acadêmico, ao estilo Benjamin Constant, quanto da politização extrema. De fato, as rusgas em torno das definições da profissão de militar e de seus padrões de excelência ganham força com as transformações da composição social do oficialato nas duas primeiras décadas do século XX, como atestam as atividades dos Jovens Turcos e de seu cavalo de batalha, a revista A Defesa Nacional.

Ao tomar em conta a baixa autonomia da carreira militar frente à lógica da política e ao mesmo tempo situar a instituição dentro de um edifício de postos, cargos, prestígio e relativa estabilidade na órbita estatal, a análise procurou igualmente tornar mais inteligíveis as lutas travadas pelos militares contra outros grupos dirigentes, em diferentes conjunturas, na busca de espaço no poder. O recurso a princípios de legitimação variados como o abolicionismo e o republicanismo, a meritocracia, a modernidade técnica e outros, vocalizados por frações do exército aglutinadas em torno de clubes, grupos e revistas, indica a um só tempo os instrumentos de que podiam valer-se em embates por prestígio e autoridade e a porosidade das fronteiras dos espaços sociais no contexto brasileiro.

\section{Referências Bibliográficas}

ALMANAK dos Oficiais Efetivos, Reformados, e Honorários da Diferentes Armas do Exército do Império do Brasil no Ano de 1855, Rio de Janeiro: Typographia Universal de Laemmert, 1855.

BADIE, B. L'État importé: essai sur l'occidentalisation de l'ordre politique. Paris: Fayard, 1992.

BADIE, B.; HERMET, Guy. Política Comparada. México: Fondo de Cultura Económica, 1993.

BANHA, P. da M. (coord.). História do Estado-Maior do Exército. Rio de Janeiro: Bibliex, 1984.

BAYART, J.-F. La greffe de l'Etat: les trajectoires du politique. Paris: Karthala, 1996.

BOURDIEU, P. La Noblesse d'État: Grandes Écoles et Esprit de Corps. Paris: Minuit, 1989. 
BOURDIEU, P.; PASSERON, J.-C. A reprodução: elementos para uma teoria do sistema de ensino. Rio de Janeiro: Francisco Alves, 1992.

; SAINT-MARTIN, M. de. Agrégation et ségrégation: le champ des grandes écoles et le champ du pouvoir. Actes de la Recherche en Sciences Sociales, (69), sept., 1987, p. 3-51.

CAILLETEAU, F.; BONNARDOT, G. Le recrutement des généraux en France, en GrandeBretagne et en Allemagne. In: SULEIMAN, E.; MENDRAS, H. (dirs.). Le Recrutement des Elites en Europe. Paris: La Découverte, 1995, p. 158-180.

CARVALHO, J. M. de. A Construção da Ordem: a elite política imperial; Teatro de Sombras: a política imperial. Rio de Janeiro: Editora da UFRJ, Relume-Dumará, $2^{a}$ ed. revisada, 1996.

A formação das almas: o imaginário da República no Brasil. São Paulo: Companhia das Letras, 1990.

As Forças Armadas na Primeira República: O Poder Desestabilizador. In: FAUSTO, B. (org.). História Geral da Civilização Brasileira - O Brasil Republicano; vol. 9. São Paulo: Difel, 1977, p. 181-234.

CARVALHO, M. T. de. Nobiliário sul-riograndense. Porto Alegre: Globo, 1937.

CARVALHO, S. de. Memórias - dados para a história do Brasil. Rio de Janeiro: O Cruzeiro, 1950.

CASTRO, C. O espírito militar: um estudo de antropologia social na Academia Militar das Agulhas Negras. Rio de Janeiro: Jorge Zahar Editor, 1990.

. Os Militares e a República: um estudo sobre cultura e ação política. Rio de Janeiro: Jorge Zahar Editor, 1995.

CHARLE, C. Les Élites de la République (1880-1900). Paris: Fayard, 1987.

CHAUSSINAND-NOGARET, G. et al. Histoire des élites en France du XVe au XXe siècle: l'honneur, le mérite, l'argent. Paris: Tallandier, 1991.

CIDADE, F. de P. Cadetes e alunos militares através dos tempos. Rio de Janeiro: Bibliex, 1961.

CORADINI, O. L. A Formação da Elite Médica no Brasil e seu Recrutamento: confronto com o caso francês. Cadernos de Ciência Política, Porto Alegre, (11), UFRGS, 1998.

. "Grandes Famílias" e Elite "Profissional" na Medicina no Brasil. Cadernos de Ciência Política, Porto Alegre, (2), UFRGS, 1995.

Regionalismo, positivismo e comunitarismo orgânico nos confrontos de elites culturais e políticas no Rio Grande do Sul (1920-1960). In: TRINDADE, H. (org.). Positivismo: teoria e prática. Porto Alegre: EDUFRGS, $3^{\text {a }}$ ed., 2007.

CUNHA, R. V. da. Estudo da Nobreza Brasileira - Cadetes. Rio de Janeiro: Arquivo Nacional, 1966.

FAORO, R. Os donos do poder: formação do patronato político brasileiro. Porto Alegre: Globo, 1958. 
KLINGER, B. Narrativas autobiográficas. Rio de Janeiro: O Cruzeiro, vol. 3, 1948.

LAGO, L. Generais da República (15 de Novembro de 1889 a 31 de Dezembro de 1943). Rio de Janeiro: Imprensa Nacional, 1944.

Os Generais do Exército Brasileiro de 1860 a 1889. Rio de Janeiro: Imprensa Nacional, 1942.

LEIRNER, P. de C. Meia-volta, volver: um estudo antropológico sobre a hierarquia militar. Rio de Janeiro: Editora Fundação Getúlio Vargas, 1995.

LOVE, J. O regionalismo gaúcho. São Paulo: Perspectiva, 1975.

MAGALHÃES, J. B. A evolução militar do Brasil - anotações para a história. Rio de Janeiro: Bibliex, 1958.

MALAN, A. S. Missão Militar Francesa de Instrução junto ao Exército brasileiro. Rio de Janeiro: Bibliex, 1988.

McCANN, F. D. The Formative Period of Twentieth-Century Brazilian Army Thought. The Hispanic American Historical Review, vol. 64 (4), nov., 1984, p. 737-765.

Soldados da Pátria: história do Exército brasileiro (1889-1937). São Paulo: Companhia das Letras, 2007.

MEDEIROS, L. T. Escola Militar de Porto Alegre (1853/1911): significado cultural. Porto Alegre: Ed. da Universidade/UFRGS, 1992.

MOREIRA, P. R. S. Inquéritos Disciplinares e Fés-de-Ofício: fontes documentais para a análise do comportamento estudantil da mocidade militar no final do Império (Escola Militar/RS). Métis (UCS), Caxias do Sul, v. 1, n. 1, p. 143-172, 2004.

MICELI, S. A elite eclesiástica brasileira. São Paulo: Difel, 1988.

MOTTA, J. Formação do oficial do Exército. Rio de Janeiro: Cia. Brasileira de Artes Gráficas, 1976.

PÉCAUT, D. Os Intelectuais e a Política no Brasil: entre o povo e a nação. São Paulo: Ática, 1990.

PEREGRINO, H. História e projeção das instituições culturais do Exército. Rio de Janeiro: José Olympio, 1967.

PINTO, L. Experiência vivida e exigência científica de objetividade. In: MERLLIÉ Dominique et al. Iniciação à prática sociológica. Petrópolis: Vozes, 1996.

PORTO ALEGRE, A. Vultos e fatos do Rio Grande do Sul. Porto Alegre: Globo, 1919.

SCHULZ, J. O Exército e o Império. In: Hollanda, S. B.; CAMPOS, P. M. (org.). História Geral da Civilização Brasileira: O Brasil Monárquico, Tomo IV, Vol. II. São Paulo: Difel, 1971, p. 235-258. SCHULZ, J. O Exército na Política: origens da intervenção militar, 1850-1894. São Paulo: Edusp, 1994. 
SCHWARZ, R. Ao vencedor as batatas: Forma literária e processo social nos inícios do romance brasileiro. São Paulo: Editora 34, 1977.

SILVA, A. P. M. da. Os Generais do Exército Brasileiro de 1822 a 1889. Rio de Janeiro: Cia. Editora Americana, 2 vol., 1940.

URICOECHEA, F. O Minotauro Imperial: a burocratização do Estado patrimonial brasileiro no século XIX. Rio de Janeiro: Difel, 1978.

WEBER, M. Economia y Sociedad: esbozo de sociología comprensiva. México: Fondo de Cultura Económica, 1996.

\section{NOTAS}

${ }^{1}$ Entre outros, Carvalho (1977), Castro (1990 e 1995), Magalhães (1958), Motta (1976) e Schulz (1994).

${ }^{2}$ As qualidades que constituíam merecimento militar para preceder à antiguidade no provimento de metade das vagas dos postos de major, tenente-coronel e coronel eram: $1^{\mathrm{a}}$ subordinação; $2^{\mathrm{a}}$ valor; $3^{\mathrm{a}}$ inteligência, zelo, instrução $e$ disciplina militar; e $4^{\text {a }}$ bons serviços prestados na paz ou na guerra. Cf. Regulamento para execução da lei n. ${ }^{\circ} 585$ de 6 de Setembro de 1850, in: Almanak dos Oficiais Efetivos, Reformados, e Honorários da Diferentes Armas do Exército do Império do Brasil no Ano de 1855, RJ, Typographia Universal de Laemmert, 1855, p. 27.

${ }^{3}$ Cf. Lei n. 585 de 6 de Setembro de 1850 e Decreto n. ${ }^{\circ} 772$ de 31 de Março de 1851, in: Almanak dos Oficiais Efetivos, Reformados, e Honorários da Diferentes Armas do Exército do Império do Brasil no Ano de 1855, RJ, Typographia Universal de Laemmert, 1855, p. 25-31.

${ }^{4}$ Esses pressupostos apoiam-se, sobretudo, nos estudos de sociologia histórica e de política comparada de Badie (1992), Badie; Hermet (1993) e Bayart (1996). Em seus trabalhos, destaca-se que a importação de modelos exógenos, além dos efeitos acima citados, tem como consequência o surgimento de um Estado híbrido, fruto do transplante de instituições estrangeiras ao interior de sociedades culturalmente diversas, de tradição completamente alheia ao modelo importado. Posto que suas condições de surgimento e de uso social nunca podem ser reproduzidas em outras situações, a estrutura implantada passa por um processo de adaptação e interpretação, necessariamente sofrendo modificações significativas, a ponto de, em muitos casos, resultar em uma deformação do paradigma original. No Brasil, trabalhos muito conhecidos, como o de Faoro (1958), Schwarz (1977) e o de Carvalho (1990), valem-se em alguma medida dessa perspectiva.

${ }_{5}^{5}$ No mesmo sentido, ver o trabalho de Uricoechea (1978, p. 68) sobre a Guarda Nacional, criada em 1831.

${ }^{6}$ Segundo informa Leirner (op. cit., p. 59), a nomenclatura empregada era "inspirada no Livro de las siete partidas, de Afonso X de Castela, um código que constitui a adaptação do direito cesarista-romano às instituições e costumes peninsulares".

${ }^{7}$ Dos sete anos de que era composto o curso da Academia (os dois primeiros anos habilitavam às armas de cavalaria e infantaria), à exceção da disciplina de História Natural, todas as outras estavam exclusivamente vinculadas às ciências exatas. Para uma apresentação e exame detalhado do currículo, ver Motta (op. cit.).

${ }^{8}$ Raros eram os professores que possuíam formação militar. Em sua maioria, tinham ou haviam tido outras ocupações, como o jornalismo, por exemplo, e exercido cargos políticos, como o de deputado, senador e governador.

${ }^{9}$ Teriam direito ao título de bacharel em Ciências Físicas e Matemáticas os alunos que possuíssem os sete anos do curso completo da Escola Militar. Também poderiam, ainda, exibir o grau de doutor naquelas ciências no caso de terem obtido aprovações plenas em todas as matérias dos referidos anos.

${ }^{10}$ Com respeito às características dos exércitos modernos, ver Max Weber (1996, p. 716 e passim).

${ }^{11}$ Pequenas unidades militares, geralmente localizadas em zonas rurais.

${ }^{12}$ O Estado-Maior do Exército (EME) existia sob essa denominação desde 1896, originário da antiga Repartição do Ajudante-General, porém até então não se constituíra como estrutura orgânica e articulada. A esse respeito, consultar Banha (1984).

${ }^{13}$ De acordo com essa reorganização, os cursos ficavam divididos da seguinte forma: Cursos de Armas, feitos nas escolas militares, para a preparação dos oficiais subalternos das armas; Cursos de Aperfeiçoamento de Armas, realizados nas Escolas de Aperfeiçoamento de Oficiais (RJ) e destinados a completar a instrução dos oficiais e aperfeiçoá-los como instrutores e comandantes de pequenas tropas; Cursos Técnicos de Artilharia e de Engenharia, com a finalidade de habilitar tenentes destas duas armas para as funções técnicas dos serviços de Material Bélico e de Engenharia; Curso de Estado-Maior, feitos na Escola de Estado-Maior (RJ) e visando à formação do quadro de oficiais de Estado-Maior, fonte de recrutamento do alto comando futuro; Curso de Revisão, destinado a manter atualizada a formação dos oficiais superiores. Cf. Motta (op. cit., p. 309) e Malan (1988, p. 250). 
${ }^{14}$ Processo simbólico de instituição de diferenças, o "reconhecimento de cadete" conferia uma série de vantagens ao detentor do título, traduzindo maiores possibilidades objetivas de ascender a uma boa posição no oficialato. A distinção de ser cadete permitia ao jovem "frequentar, simultaneamente, a roda dos oficiais e a dos sargentos", e não era "nada espantoso que fosse objeto das atenções governamentais (CUNHA, op. cit., p. 73). Além disso, "não fariam sentinela nos quartéis; e concorreriam com os sargentos e forriéis nos serviços externos. Podiam ser promovidos sem tempo determinado de praça (MAGALHÃES, 1950, p. 501, apud URICOECHEA, op. cit., p. 79).

${ }^{15}$ Entre em 1822 e 1860 , pouco mais da metade dos generais do Exército não eram brasileiros, enquanto que entre 1861 e 1889 este percentual cai para $12,50 \%$.

${ }^{16}$ A utilização desses recursos na composição de carreiras bem sucedidas é explorada com detalhes em Seidl (2008).

${ }^{17}$ Para uma análise centrada em outra grande corporação nacional na República Velha, a Igreja, consultar Miceli (1988).

${ }^{18}$ Para uma exposição detalhada desse processo, com suas tensões e disputas entre grupos de oficiais, consultar a extensa obra de McCann (2009).

${ }^{19}$ O primeiro capítulo do livro de Schulz, publicado originalmente em 1974, intitula-se "1850 - Uma carreira se abre ao talento".

${ }^{20} \mathrm{Ou}$, como afirma Bourdieu (1989, p. 57), "essa colocação dos agentes em posições hierarquizadas constitui por sua vez um dos mecanismos maiores da transformação do capital herdado em capital escolar".

${ }^{21}$ Os dados coletados por Schulz (op. cit., p. 210-211) em almanaques militares confirmam esta expansão. Já em 1857, todos oficiais de engenharia, artilharia e estado-maior de primeira classe acima do posto de segundo-tenente haviam concluído seus respectivos cursos de armas. Isso não era válido, porém, para os oficiais de infantaria e cavalaria, visto que dos 62 oficiais superiores daquele ano, apenas 5 terminaram seus cursos. Em 1910, por outro lado, 131 dos 170 oficiais superiores da infantaria e da cavalaria haviam feito o curso que lhes cabia. Entre os generais na ativa em 1855 , apenas 14 , de um grupo de 29 , haviam obtido o curso da arma, enquanto que por volta de 1891 esse número passou para 24, de um total de 43 generais, e desde então continuou a crescer.

${ }^{22}$ Ainda assim, não se poderia falar de tendência homogênea nos diferentes estados do país. O caso do Rio Grande do Sul - seguramente maior exemplo de reprodução endógena e, sobretudo, baseada em grupos familiares, no Exército revela alto grau de manutenção de filhos de oficiais de patente elevada entre seus generais no período 1890-1930 $(56,73 \%)$. Vide quadros II e III.

${ }^{23}$ Assim, por exemplo, entre 1871 e $1889,6,06 \%$ dos ministros eram militares, percentual que salta para 40,00 entre 1894 e 1910; entre os congressistas, em 1860, apenas 1,6\% eram militares, número que chega a 19,3\% em 1890; no Senado, os militares eram 3,17\% em 1889 e chegaram a 17,58\% em 1980. A evolução desses dados para todo período imperial e primeiras décadas da República pode ser vislumbrada em Carvalho (1977 e 1996).

${ }^{24} \mathrm{O}$ debate acadêmico em torno do positivismo no Brasil tem diversos matizes. Nossa posição coincide com as de Pécaut (1990, p. 60-66) e de Coradini (2007: esp. p. 412), para quem o que se chamou de positivismo, no Brasil, referese muito mais a certo tipo de militarismo, associado a determinadas posições de origem social e a um tipo específico de escolarização e de ethos militar.

${ }^{25}$ Também, já em 1880 havia sido fundada em Porto Alegre, por alunos-oficiais em sua maioria, a Sociedade Emancipadora Rio Branco, cuja finalidade principal consistia em lutar pelo fim do regime de escravidão no país. Cf. Moreira (2004). Para elementos da história das escolas militares e seu ambiente intelectual, consultar Peregrino (1967).

${ }^{26}$ Sem dúvida, o positivismo castilhista representa um dos melhores exemplos dos efeitos de adaptação de filosofias e ideologias a novos contextos. Servia, antes de tudo, à legitimação de um poder forte e não representativo, mas também não defendia a separação entre o poder espiritual e o temporal nem buscava a afirmação da liberdade de expressão. Além disso, não questionava o individualismo, o caráter científico do poder e a superioridade do bem comum sobre interesses particulares. Em síntese, convergia abertamente para uma organização autoritária da sociedade. Cf. Pécaut (1990, p. 60-61) e Love (1975).

${ }^{27}$ Jovens Turcos foi o apelido dado aos oficiais enviados em missões de dois anos a Alemanha (1906, 1908 e 1910) para servirem arregimentados no exército alemão. Muitos dos oficiais tornaram-se generais e ocuparam posições de destaque no Exército e na política nacional. Klinger, juntamente com Leitão de Carvalho e Euclides de O. Figueiredo, pai de um futuro presidente da República, participou da última missão, entre 1910-1912.

Artigo recebido em 09/2010. Aprovado em 11/2010. 